\title{
Childhood Obesity Research Demonstration Project: Cross-Site Evaluation Methods
}

\author{
Daniel P. O'Connor, PhD,' Rebecca E. Lee, PhD,' Paras Mehta, PhD, \\ Debbe Thompson, PhD, ${ }^{4}$ Alok Bhargava, $\mathrm{PhD},{ }^{5}$ Coleen Carlson, $\mathrm{PhD},{ }^{3}$ Dennis Kao, $\mathrm{PhD}^{6}$ \\ Charles S. Layne, PhD,' Tracey Ledoux, PhD,' Teresia O'Connor, MD, MPH, \\ Hanadi Rifai, PhD,' Lauren Gulley, BS, Allen M. Hallett, BS,' Ousswa Kudia, MPH,' \\ Sitara Joseph, MPH,' Maria Modelska, MPA,' Dana Ortega, MS,' Nathan Parker, MPH,' \\ Andria Stevens, MPH,' and the EC-CORD (BETTER Policies) Team
}

\section{Abstract}

Introduction: The Childhood Obesity Research Demonstration (CORD) project links public health and primary care interventions in three projects described in detail in accompanying articles in this issue of Childhood Obesity. This article describes a comprehensive evaluation plan to determine the extent to which the CORD model is associated with changes in behavior, body weight, BMI, quality of life, and healthcare satisfaction in children 2-12 years of age.

Design/Methods: The CORD Evaluation Center (EC-CORD) will analyze the pooled data from three independent demonstration projects that each integrate public health and primary care childhood obesity interventions. An extensive set of common measures at the family, facility, and community levels were defined by consensus among the CORD projects and EC-CORD. Process evaluation will assess reach, dose delivered, and fidelity of intervention components. Impact evaluation will use a mixed linear models approach to account for heterogeneity among project-site populations and interventions. Sustainability evaluation will assess the potential for replicability, continuation of benefits beyond the funding period, institutionalization of the intervention activities, and community capacity to support ongoing program delivery. Finally, cost analyses will assess how much benefit can potentially be gained per dollar invested in programs based on the CORD model.

Conclusions: The keys to combining and analyzing data across multiple projects include the CORD model framework and common measures for the behavioral and health outcomes along with important covariates at the individual, setting, and community levels. The overall objective of the comprehensive evaluation will develop evidence-based recommendations for replicating and disseminating community-wide, integrated public health and primary care programs based on the CORD model.

\section{Introduction}

$\mathbf{T}$ The Childhood Obesity Research Demonstration (CORD) project supports the development, delivery, and evaluation of three demonstration projects that use an integrated approach to implement multilevel, multisector environmental systems and policy changes that are intended to impact childhood obesity. All three projects link services across settings for at-risk families using community health workers (CHWs). The ultimate goal is to

\footnotetext{
'Department of Health and Human Performance, Texas Obesity Research Center, University of Houston, Houston, TX.

${ }^{2}$ College of Nursing and Health Innovation, Arizona State University, Phoenix, AZ.

${ }^{3}$ Department of Psychology, Texas Institute for Measurement, Evaluation, and Statistics, University of Houston, Houston, TX.

${ }^{4}$ USDA/ARS Children's Nutrition Research Center, Baylor College of Medicine, Houston, TX.

${ }^{5}$ School of Public Policy, University of Maryland, College Park, MD.

${ }^{6}$ Graduate College of Social Work, University of Houston, Houston, TX.

${ }^{7}$ Department of Civil and Environmental Engineering, University of Houston, Houston, TX.
} 
provide evidence-based recommendations for applying the CORD model in broader populations and contexts. The three demonstration projects and respective interventions are described in detail in accompanying articles in this issue of Childhood Obesity and include: the Mass in Motion Kids project in Massachusetts (MA-CORD) ${ }^{1}$; Our Choice/Nuestra Opción project in California $(\mathrm{CA}-\mathrm{CORD})^{2}$; and the Texas CORD project (TX-CORD). ${ }^{3}$ The CORD Evaluation Center (EC-CORD) will provide a comprehensive evaluation of the pooled data across the three CORD demonstration projects. This article describes the general framework and plan for the EC-CORD comprehensive evaluation.

\section{Methods}

\section{Evaluation Framework}

Although the three projects all utilize the CORD model framework, ${ }^{4-8}$ the resulting project-specific designs, populations, interventions, planned measures, implementation schedules, and assessment plans vary considerably. Unlike a multicenter trial that has a uniform intervention protocol, each project includes activities and interventions tailored to the specific communities in which the project is im- plemented. To address these challenges, EC-CORD will use a general logic model (Fig. 1) and an extensive set of common measures for outcomes, key variables, and processes at multiple levels.

The logic model includes the inputs, activities, and short-term, medium-term, and long-term outcomes used to describe the CORD project communities, interventions, and results across multiple sectors in a consistent way. Consequently, it identifies and organizes the essential elements of the projects that require measurement and evaluation. In addition, the model provides the structure to explain how the integrated intervention components produce changes in behavior and health.

The CORD consortium, made up of EC-CORD investigators, the demonstration project investigators, and CDC advisors, identified a set of common measures using a collaborative process during the first year of the CORD project. $^{8,9}$ Common measures from previously validated instruments were selected for the CORD target outcomes: fruit and vegetable consumption; sugar-sweetened beverage and water consumption; physical activity (PA); screen time; and sleep duration. In addition, the set of common measures includes indicators that capture important characteristics of

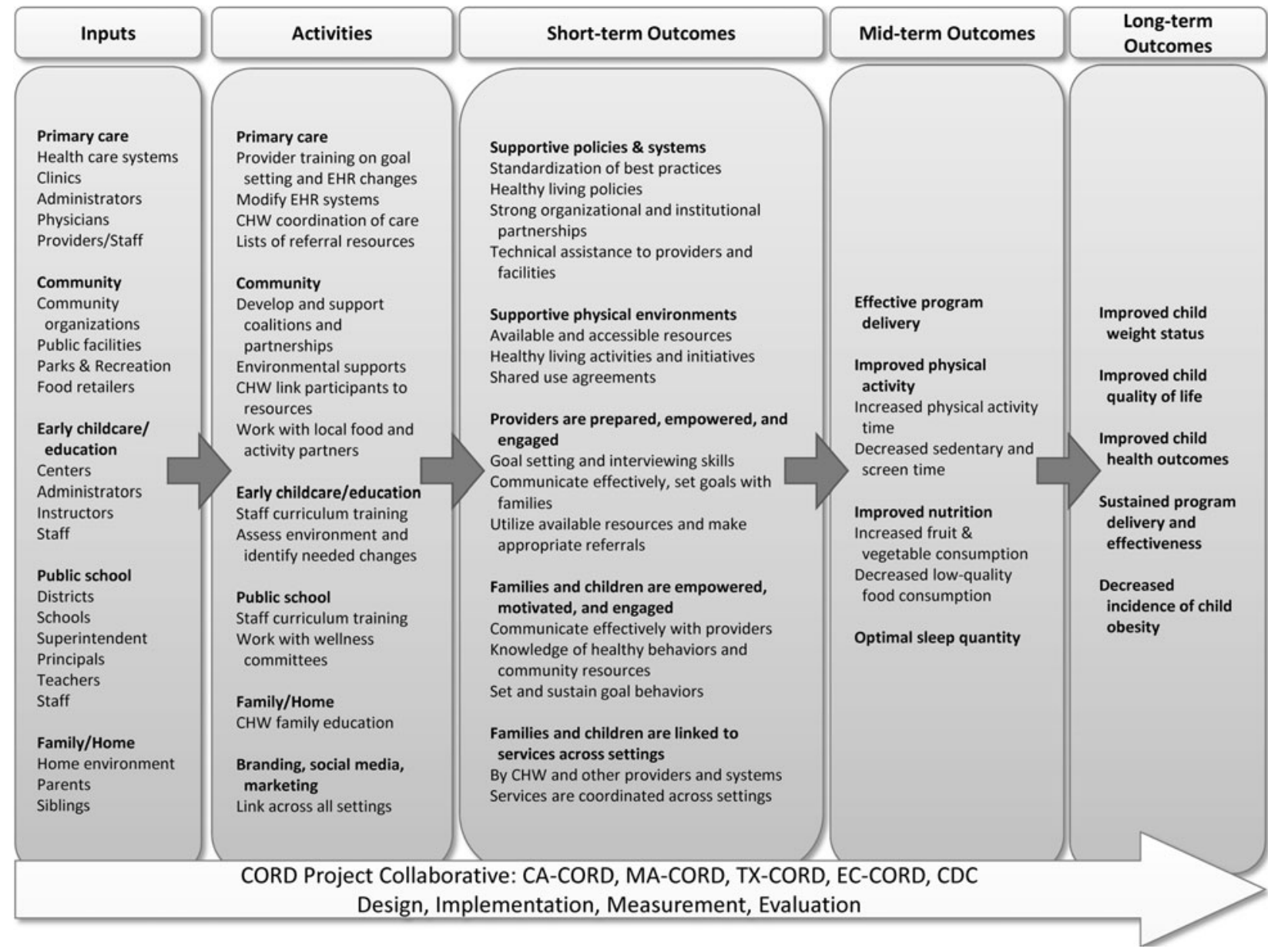

Figure 1. Childhood Obesity Research Demonstration project evaluation logic model. EHR, electronic health record; CHW, community health worker. 
communities (e.g., sociodemographics), facilities (e.g., healthcare centers and schools), providers (e.g., physicians and teachers), families and children (e.g., education, income, weight status, and health-related behaviors), as well as aspects of process, sustainability, and costs. Each project collects and reports all of these common data as well as additional project-specific data to EC-CORD for warehousing and use in the comprehensive evaluation. Developing and implementing a consistent data collection protocol with an extensive and comprehensive set of common measures at multiple levels for multiple outcomes and covariates has been described as "prospective harmonization" 10 or "prospectively planned pooled analysis"11 and represents the optimal situation for pooled data analysis. ${ }^{12,13}$

EC-CORD also developed a taxonomy for coding the different interventions in a comparable way across the three projects. Table 1 shows how the intervention components across the three CORD projects will be coded into one of three broad categories that reflect components of the CORD model: Public Health; Primary Care; and Primary Care Plus. ${ }^{8}$ Public health $(\mathrm{PH})$ includes activities and programs in multiple community settings, such as schools, early child care education centers, and recreation centers, that are intended to improve the health of the general public. For example, each CORD project is using evidence-based health promotion programs in elementary schools, such as Sports, Play, and Active Recreation for Kids in CA-CORD; Eat Well Keep Moving in MA-CORD; and Coordinated Approach to Child Health in TX-
CORD. ${ }^{1-3}$ Similar evidence-based programs and associated integrated activities are delivered in early child care education centers and various community venues as described in greater detail in the accompanying articles in this issue. ${ }^{1-3}$ Primary care (PC) involves obesity primary prevention efforts through changes to clinic policies, systems, and environments and the practices of medical professionals that are intended to affect all families at the participating clinics. A PC activity implemented by all three CORD projects is the changes to electronic health record systems to provide prompts related to diagnosis of obesity and links to resources the primary care physician may use to counsel the family. ${ }^{1-3}$ Primary Care Plus (PC Plus) augments PC with additional, secondary prevention care and activities provided only to families with children who are overweight or obese (i.e., BMI $\geq 85$ th percentile for age and sex). Examples of PC Plus include programs to which families with an obese child are referred by the PC providers, as described in the accompanying articles from each project in this issue of Childhood Obesity: the intensive community health worker-based program in CA$\mathrm{CORD}^{2}$; the healthy weight clinics in $\mathrm{MA}-\mathrm{CORD}^{1}$; and the Mind, Exercise, Nutrition, Do It program ${ }^{14}$ in TX-CORD. ${ }^{3}$

Across the three CORD project designs, children and families will be exposed to various combinations of these three components, as shown in Table 1, including PH only, PC Plus only, $\mathrm{PH}$ with $\mathrm{PC}, \mathrm{PH}$ with $\mathrm{PC}$ Plus, or none (comparison cohorts). Using this taxonomy will allow for describing the interventions in a consistent way and coding

\section{Table I. Combinations of Childhood Obesity Research Demonstration (CORD) \\ Intervention Components for Children in the Longitudinal Cohorts \\ (Assessed at Baseline and 12 Months) Who Are $\geq 85$ th BMI Percentile \\ by Demonstration Project Site and Community}

\begin{tabular}{|c|c|c|c|c|c|c|c|c|}
\hline & \multicolumn{3}{|c|}{ CA-CORD $(n=\mid 200)$} & \multicolumn{3}{|c|}{ MA-CORD $(n=200)$} & \multicolumn{2}{|c|}{ TX-CORD $(n=576)$} \\
\hline Intervention component & Brawley & El Centro & Calexico & Fitchburg & New Bedford & Lowell & Austin & Houston \\
\hline I. CORD PH+PC Plus & $\checkmark$ & $\checkmark$ & - & $\checkmark$ & $\checkmark$ & - & $\checkmark$ & $\checkmark$ \\
\hline 2. $\mathrm{CORD} \mathrm{PH}+\mathrm{PC}$ & $(\checkmark)$ & $(\checkmark)$ & - & $\checkmark$ & $\checkmark$ & - & $\checkmark$ & $\checkmark$ \\
\hline 3. CORD PH & $\checkmark$ & $\checkmark$ & - & $(*)$ & $(*)$ & - & $(*)$ & $(*)$ \\
\hline 4. CORD PC Plus & - & - & $\checkmark$ & $(\checkmark)$ & $(\checkmark)$ & - & $(\checkmark)$ & $(\checkmark)$ \\
\hline 5. CORD PC & - & - & $(\checkmark)$ & $(\checkmark)$ & $(\checkmark)$ & - & $(\checkmark)$ & $(\checkmark)$ \\
\hline 6. No CORD Intervention & - & - & $\checkmark$ & - & - & $\checkmark$ & - & - \\
\hline
\end{tabular}

$\checkmark$ Groups described in the initial project designs (i.e., planned intervention exposure).

$(\checkmark)$ Groups of intervention combinations outside of the projects' initial design groups based on actual intervention exposure.

$\left(^{*}\right)$ Cross-sectional baseline and I2-month data available, including a subset of the CORD common measures; no longitudinal data available.

- A community without the respective intervention combination.

CORD PH: Public health interventions in the CORD projects that are intended to improve the health of the general public.

CORD PC: Primary care interventions in the CORD projects that are intended to affect all families at the participating clinics.

CORD PC Plus: Primary care interventions augmented by secondary prevention activities in the CORD projects that are intended only for families with children who are overweight or obese.

CA-CORD, MA-CORD, TX-CORD: the CORD projects implemented in California, Massachusetts, and Texas, respectively. 
the combinations of interventions to which participants were assigned by design. ${ }^{15}$ This taxonomy also will allow coding of observed combinations outside of the initial project designs, such as "PC only" if a CORD study participant attends a participating PC clinic, but does not live in the area or attend one of the local schools where the CORD PH intervention is delivered. This allows analyses to be conducted on an intention-to-treat basis to evaluate results that account for some participants not receiving or completing the intended interventions, and to be conducted on a "per protocol" basis to evaluate results from a known exposure to the respective intervention activities.

\section{Process Evaluation}

To conduct a thorough process evaluation across the three CORD demonstration projects, three common process evaluation components will be assessed: reach, ${ }^{16}$ dose delivered, ${ }^{16,17}$ and fidelity, ${ }^{16,17}$ each defined in Table 2 . The use of these constructs in process evaluation has been well documented in similar multiproject studies, such as the HEALTHY study for the prevention of type 2 diabetes in middle school students. ${ }^{18}$

During the CORD planning year, each project provided information regarding the process data they were planning to collect and their methods of data collection (e.g., audits, observations, surveys, and interviews). This information was then compared across projects, and only data that are consistently and uniformly collected across communities and settings will be used in analyses and reported in the evaluation. The projects use standardized process evaluation data collection forms, definitions, and procedures developed and distributed to the projects by the EC-CORD to facilitate data reporting and ensure consistency for ECCORD's pooled evaluation.

Following the CORD Model's framework for implementing changes in practices, systems, and environments that influence obesity-related behaviors and health of children and families, ${ }^{8}$ the CORD projects deliver their interventions through existing providers (e.g. doctors and teachers) in specific settings and institutions (e.g. clinics and schools). Program implementation and delivery to families depends on the training and support that existing providers received from the study. The intent of training is to create prepared and engaged providers who, in turn, deliver the intervention activities designed to prepare and motivate families to engage in healthy living behaviors. Therefore, process evaluation components will be assessed at two levels: researcher- (i.e., CORD investigators and project teams) to-provider (i.e., individuals and organizations delivering CORD activities in each setting) and provider-tofamily (i.e., parents and children). With this approach, both providers and families will be defined as participants, which allows for a more thorough process evaluation.

The process evaluation components are measured in each of the settings where interventions are delivered: primary care clinics; early child care/education (child care) centers, public schools, and community institutions. Three process measures will be assessed for each component: provider training; family and patient education; and policy, systems, or environmental changes. An "other" measure category will also be included to capture additional information related to program implementation that did not fit into the other measures. This complex approach to process evaluation will provide a comprehensive and consistent view of CORD implementation across the three projects.

The total number of providers trained to deliver the CORD interventions in each setting and the total number of children and families participating in one or more CORD activities will be counted in each community at the end of each project year to calculate reach. The data from the project will be combined with local, state, and US Census data and information from publicly available sources (National Center for Education Statistics [NCES] for public school demographics, Environmental Systems Research Institute [Esri] ArcGIS Business Analyst to identify healthcare and early child care and education facilities) to determine the number of eligible institutions and families in each community. These data will then be compared to the counts of participating CORD providers, children, and families to describe the reach of the CORD project into each community.

The dose delivered for each intervention will be assessed by aggregating data from activity logs and checklists maintained by the projects as they deliver the interventions. This analysis will describe what the project

\begin{tabular}{|c|c|c|}
\hline Component & Definition & Example measure \\
\hline Reach & $\begin{array}{l}\text { To what extent did CORD attract } \\
\text { the intended participants? }\end{array}$ & $\begin{array}{l}\text { Total number of eligible elementary schools who participate } \\
\text { in CORD project compared with number of eligible schools in area. }\end{array}$ \\
\hline Dose-delivered & $\begin{array}{l}\text { What activities were delivered } \\
\text { to the intended providers and families? }\end{array}$ & $\begin{array}{l}\text { Planned and unplanned activities delivered to providers by CORD } \\
\text { researchers and staff (e.g., number of trainings provided, number } \\
\text { of staff trained, training objectives delivered, and materials given to providers). }\end{array}$ \\
\hline Fidelity & $\begin{array}{l}\text { What proportion of CORD activities } \\
\text { were delivered as planned? }\end{array}$ & $\begin{array}{l}\text { How often was the CORD template used in the electronic medical } \\
\text { record when a child was seen for a well-child exam whose BMI was } \geq 85 \text { th \%tile? }\end{array}$ \\
\hline
\end{tabular}

CORD, The Childhood Obesity Research Demonstration project. 
investigators delivered to their providers as well as what those providers delivered to families and children. To assess fidelity, a priori lists of planned activities within each setting will be compared to activities actually delivered.

\section{Impact Evaluation}

The impact evaluation will estimate the longitudinal effects of the CORD interventions on child behaviors (consumption of fruits and vegetables, water, and sweetened beverages from School Physical Activity and Nutrition [SPAN] survey ${ }^{19}$; "past 7 days" PA from the National Health and Nutrition Examination Survey [NHANES]; and select items from the Pediatric Sleep Questionnaire ${ }^{20}$ ), body weight (measured by trained examiners), and quality of life (Pediatric Quality of Life Inventory ${ }^{21}$ ). The longitudinal data collected at two of the three projects will include only children at or above the 85th BMI age- and sex-specific percentile, which will limit the cross-site impact evaluation to the effects among overweight and obese children. In addition, given that the interventions and settings differ for preschool (ages 2-5 years) and school-age (ages 5-12 years) children, the analyses will be conducted separately for each age group. Mixed-models analyses of covariance and other methods will be used to estimate the 12-month change in outcomes for children and families with the respective baseline measure as a covariate and random effects to account for clustering within projects and settings (e.g., children attending the same schools). Such models can be estimated by maximum likelihood methods when only a few time observations are available on the subjects. ${ }^{22,23}$ Coefficients in the models will quantify how the interventions are associated with 12month changes in the measured behavioral and health outcomes.

Various combinations of the intervention components (PH, PC, and PC Plus) are implemented within and across the eight CORD communities. For the purposes of the cross-site evaluation, the unit of intervention assignment will be defined by the combinations of community and designed intervention groups, as represented by check marks in Table 1. Because the communities and catchment areas were selected by the demonstration project investigators using population-level matching on a wide range of demographic and socioeconomic variables, the initial design groups are adequately sized, matched, and balanced to facilitate within-project comparisons., ${ }^{2,9}$ Consequently, including categorical variables representing the units of assignment in the analytical model will provide a method for incorporating the heterogeneity among projects and communities into the analysis of the pooled data. This statistical approach is consistent with existing recommendations for pooled analysis and meta-analysis of individual-level data from different studies. ${ }^{11-13,24,25}$ Including the intervention components and units of assignment as factors in the statistical model will allow for estimating effect sizes of the respective intervention combinations relative to one another while accounting for heterogeneity among the communities. Failing to account for the heterogeneity among the projects and communities would produce inflated type I and inferential errors. ${ }^{24,26}$ Likelihood ratio tests will be applied to assess the appropriateness of pooling the data. ${ }^{22}$

The target enrollment of the longitudinal cohorts is over 2000 families, with an expectation of at least 20 observations per intervention cell in Table 1. Consequently, given that each row representing a particular intervention contains multiple communities and each project was powered to detect small-to-medium differences among intervention arms, there should be adequate sample size to include a number of select covariates in the model and evaluate the effect sizes with reasonable precision.

As an example, the first row in Table 1 represents the implementation of the full CORD model with integrated $\mathrm{PH}$ and PC Plus interventions. The average outcome across the respective groups in this row may be compared to the average outcome of one of the other rows or combinations of rows to answer important questions about the impact of the CORD project in these communities. The CORD model posits that the fully integrated interventions in row 1 (PH and PC Plus) should result in greater improvements in behaviors and weight over time. Thus, comparing row 1 to the average observed in rows 3 through 5 (PH only, PC Plus only, and PC only) will quantify the difference in response between the full CORD model and responses in groups exposed to only one of the intervention components.

Selection bias and clustering are key issues with nonrandom assignment to intervention conditions, as is the case for two of the three CORD projects. The CORD communities and respective families differ considerably on a number of important factors that may be related to their response to the various CORD interventions. Table 3 shows the measures for families ${ }^{27-30}$ and Table 4 shows the measures for children ${ }^{27,29,31-34}$ that will be used to assess the multidimensional differences in the CORD samples among projects. Similarly, variability in program implementation and existing practices in the 90 child care centers and 103 schools participating across all three CORD projects will likely be associated with the measured outcomes, and the enrolled children will be clustered within these facilities. Thus, random effects representing the child care centers and schools will be included in the analytical model. Tables 5 and 6 show the facility-level covariates for child care centers ${ }^{35,36}$ and schools, ${ }^{37-40}$ respectively, that will be used to describe and assess heterogeneity in these settings. Finally, measures of policy, systems, practices, and process differences across the 17 participating clinics, as shown in Table $7,{ }^{41}$ and eight communities, as shown in Table $8,{ }^{42}$ will provide further contextual information for interpreting results. ${ }^{43}$

\section{Sustainability Evaluation}

Sustainability determines whether proposed project activities can be sustained by the community beyond the end of the funding period. ${ }^{44}$ Evaluating sustainability can help 


\section{Table 3. Family and Home Environment Measures}

\begin{tabular}{|c|c|c|}
\hline Measures & Example items & Method source(s) \\
\hline Parent BMI & Measured height and weight & $\begin{array}{l}\text { CORD BMI/Anthropometric Data Collection Form } \\
\text { NHANES Anthropometry Procedure Manual }{ }^{25}\end{array}$ \\
\hline Parenting behaviors & $\begin{array}{l}\text { I limit the amount of time my child } \\
\text { watches TV or videos to } 2 \text { hours or less per day. }\end{array}$ & $\begin{array}{l}\text { CORD Parent Survey } \\
\text { PEAS Scale }\end{array}$ \\
\hline $\begin{array}{l}\text { Income, education, marital status, } \\
\text { household size, race/ethnicity }\end{array}$ & $\begin{array}{l}\text { What is the highest grade or year } \\
\text { of school you completed? }\end{array}$ & $\begin{array}{l}\text { CORD Parent Survey } \\
\text { BRFSS } 201 \mathrm{I}^{27}\end{array}$ \\
\hline $\begin{array}{l}\text { Acculturation (years living } \\
\text { in the United States) }\end{array}$ & $\begin{array}{l}\text { If born in another country, how many } \\
\text { years have you lived in the US? }\end{array}$ & $\begin{array}{l}\text { CORD Parent Survey } \\
\text { PEAS Scale }\end{array}$ \\
\hline SNAP or WIC participation & $\begin{array}{l}\text { Which of the following types of assistance } \\
\text { does your family receive? (WIC, food stamps/ } \\
\text { SNAP/EBT, free/reduced meals at school) }\end{array}$ & $\begin{array}{l}\text { CORD Parent Survey } \\
\text { NHANES }{ }^{28}\end{array}$ \\
\hline Health insurance and type & $\begin{array}{l}\text { Do you have any kind of healthcare coverage, } \\
\text { including health insurance, prepaid plans such } \\
\text { as HMOs, or government plans such as Medicare } \\
\text { or Indian Health Services? }\end{array}$ & $\begin{array}{l}\text { CORD Parent Survey } \\
\text { BRFSS } 201 \mathrm{I}^{27}\end{array}$ \\
\hline
\end{tabular}

SNAP, Supplemental Nutrition Assistance Program; WIC, Special Supplemental Nutrition Program for Women, Infants, and Children; TV, television; EBT, electronic benefit transfer; HMOs, health maintenance organizations; CORD, the Childhood Obesity Research Demonstration project; NHANES, the National Health and Nutrition Examination Survey; PEAS, the Parenting strategies for Eating and Activity Scale; BRFSS, Behavioral Risk Factor Surveillance System.

to determine how programs based on the CORD model might be maintained, enhanced, or changed over time. Sustainable programs demonstrate replicability and ongoing continuation of benefits through institutionalization of efforts supported by community capacity. ${ }^{45,46}$ Example measures and data sources are presented in Table 9.

Replicability indicates the likelihood that a program can be repeated successfully and is defined, in part, by the complexity and adaptability of program elements that are necessary to reproduce the program. As suggested by the examples in Table 9, each demonstration project includes numerous components that will be counted and categorized using the Program Components Checklist. The Program Components Checklist describes which aspects of interventions were planned and implemented with fidelity in each project. Comparisons among projects will determine relative levels of complexity (i.e., the number of intervention aspects implemented), and by extension, the degree of adaptability of each program. Information on complexity will be triangulated with information gleaned from interviews of participating key informants to measure the extent to which new and existing activities, resources, and materials have been incorporated into the programs. ${ }^{44}$ Key informants include leaders among local community

\section{Table 4. Child-Specific Measures}

\begin{tabular}{|c|c|c|}
\hline Measures & Example items & Method source(s) \\
\hline Child BMI, z-score & Measured height and weight & $\begin{array}{l}\text { CORD BMI Child Form } \\
\text { NHANES Anthropometry Procedure Manual }{ }^{25} \\
\text { State of Alaska: Measuring Height/Weight } \\
\text { and Calculating BMI Guidelines for Schools }{ }^{29} \\
\text { BMI Surveillance in New Mexico: A Training } \\
\text { Manual for Measuring Height and Weight in Schools }{ }^{30}\end{array}$ \\
\hline Child age, sex, ethnicity & How old are you? & $\begin{array}{l}\text { CORD Child Survey } \\
\text { YRBSS 201 }{ }^{31}\end{array}$ \\
\hline Health Insurance and type & $\begin{array}{l}\text { What type of health insurance was } \\
\text { [name of child] covered by in the last year? }\end{array}$ & $\begin{array}{l}\text { CORD Parent Survey } \\
\text { BRFSS } 2011^{27}\end{array}$ \\
\hline $\begin{array}{l}\text { Child birthplace } \\
\text { (US vs. non-US) }\end{array}$ & In what country was your child born? & $\begin{array}{l}\text { CORD Parent Survey } \\
\text { REACH US }{ }^{32}\end{array}$ \\
\hline
\end{tabular}

CORD, the Childhood Obesity Research Demonstration project; NHANES, the National Health and Nutrition Examination Survey; YRBSS, Youth Risk Behavior Surveillance System; BRFSS, Behavioral Risk Factor Surveillance System; REACH US, Racial and Ethnic Approaches to Community Health across the US. 


\section{Table 5. Early Childcare and Education Center-Level Measures}

\begin{tabular}{|c|c|c|}
\hline Measures & Example items & Method source(s) \\
\hline $\begin{array}{l}\text { Nutrition, physical activity, and health } \\
\text { practices and environments }\end{array}$ & $\begin{array}{l}\text { Fruit is offered canned in own juice } \\
\text { (no syrups), fresh, or frozen. }\end{array}$ & NAP SACC self-assessment tool ${ }^{33}$ \\
\hline Number of children attending & $\begin{array}{l}\text { How many children are currently } \\
\text { enrolled in your center or school? }\end{array}$ & $\begin{array}{l}\text { Childcare Center Director Surveys } \\
\text { Early Childhood Longitudinal Study-Preschool } \\
\text { Center Director Questionnaire }\end{array}$ \\
\hline Number of full-time teachers/staff & $\begin{array}{l}\text { How many teachers are currently } \\
\text { employed in your center or school? }\end{array}$ & $\begin{array}{l}\text { Childcare Center Director Surveys } \\
\text { Early Childhood Longitudinal Study-Preschool } \\
\text { Center Director Questionnaire }\end{array}$ \\
\hline
\end{tabular}

NAP SACC, the Nutrition and Physical Activity Self-Assessment for Child Care assessment tool.

partners, healthcare clinics, demonstration project staff, and school administrators who have been involved in delivering and supporting the multicomponent programs. At least one individual from each setting in each community (3-5 per CORD community) will provide information through interviews as sites approach the end of project implementation.

The potential for continuation of benefits is the extent to which initial program effects reach beyond the scope of the project and continue to have impact after the project funding period concludes. The potential for continuation of benefits will be operationalized by the following factors that suggest ease and reach of implementation: provider and organization attrition; adherence to CORD activities; reach beyond the original intended sample; and long-term population behavioral and health outcomes associated with the presence of the program in a community. For example, as demonstrated in Table 9, interviews from principal investigators at each project will be used to assess extension of program components beyond the original sample. Publicly available geographically linked data (e.g., from the CDC's Behavioral Risk Factor Surveillance System and the USDA's Food Access Research Atlas) on estimates of community health indicators (e.g., adult obesity rates) and obesity-related health behaviors (e.g., PA and dietary habits) will be accessed to provide insight on the potential reach and impact beyond the project communities and samples. Although it will be difficult to evaluate the direct effects of the program on these macro-level indicators, stronger population-level improvements in health may indicate a higher chance of program sustainability. ${ }^{47}$

Institutionalization is defined by the degree of integration of a program into existing organizational policies and practices that might include changes in organizations, policies, and practices that support or enforce adoption of CORD program activities or systems. ${ }^{47}$ Programs that become well integrated, with high levels of support and enforcement, are more likely to succeed and be sustained. For example, as presented in Table 9, the level of support for implementation from participating organizations can be gleaned from in-depth interviews of key informants at each project. These interviews may also indicate the degree of diffusion of program functions and activities or policy changes that may have occurred, such as modifications to

\section{Table 6. School-Level Measures}

\begin{tabular}{|c|c|c|}
\hline Measures & Example items & Method sources(s) \\
\hline School environment and policies & $\begin{array}{l}\text { Does your school or school district } \\
\text { have a wellness committee? } \\
\text { In addition to PE classes and recess periods, } \\
\text { do classroom teachers provide regular } \\
\text { physical activity breaks during the school day? }\end{array}$ & $\begin{array}{l}\text { School Leader Surveys } \\
\text { Healthy Schools Inventory worksheet }{ }^{35} \\
\text { SPAN school survey }\end{array}$ \\
\hline Number of children enrolled & Reported count of children enrolled & $\begin{array}{l}\text { School Leader Surveys } \\
\text { Common Core of Data (CCD) database-US } \\
\text { Department of Education's NCES }\end{array}$ \\
\hline Number of full-time teachers & Reported count of full-time teachers & $\begin{array}{l}\text { School Leader Surveys } \\
\text { Common Core of Data (CCD) database-US } \\
\text { Department of Education's NCES }\end{array}$ \\
\hline Average $\mathrm{BMI}$ percentile & Measured height and weight & CDC Body Mass Index ${ }^{38}$ \\
\hline Percent children on free meals programs & $\begin{array}{l}\text { Does your school offer national breakfast } \\
\text { and lunch? (free/reduced meals) }\end{array}$ & $\begin{array}{l}\text { School Leader Surveys } \\
\text { Common Core of Data (CCD) database-US } \\
\text { Department of Education's NCES }\end{array}$ \\
\hline
\end{tabular}

PE, physical education; SPAN, the School Physical Activity and Nutrition survey; NCES, National Center for Education Statistics. 


\section{Table 7. Healthcare Clinic-Level Measures}

\begin{tabular}{|c|c|c|}
\hline Measures & Example items & Method sources(s) \\
\hline Clinic environmental audit responses & $\begin{array}{l}\text { Does the facility contain vending machine(s) } \\
\text { to buy snacks or beverages within the clinic? }\end{array}$ & $\begin{array}{l}\text { CORD Vending Machine Inventory } \\
\text { CORD Healthcare Clinic Survey } \\
\text { Vending Machine Audit Tool }\end{array}$ \\
\hline Patient volume & $\begin{array}{l}\text { What is the average number of pediatric patients seen } \\
\text { in your clinic over the past } 6 \text { months? }\end{array}$ & $\begin{array}{l}\text { Clinic practice and financial records } \\
\text { CORD Healthcare Clinic Survey }\end{array}$ \\
\hline Number of FTE physicians & $\begin{array}{l}\text { How many FTE healthcare providers who } \\
\text { provide care to children work at this clinic? }\end{array}$ & $\begin{array}{l}\text { CORD Healthcare Clinic Survey } \\
\text { Adapted from Swift Worksite Assessment } \\
\text { and Translation Interview Guide: Program } \\
\text { Managers and Key Program Staff }\end{array}$ \\
\hline $\begin{array}{l}\text { Number of allied health caregivers } \\
\text { to support obesity management }\end{array}$ & $\begin{array}{l}\text { How many FTE healthcare providers who } \\
\text { provide care to children work at this clinic? }\end{array}$ & $\begin{array}{l}\text { CORD Healthcare Clinic Survey } \\
\text { Swift Worksite Assessment and Translation } \\
\text { Interview Guide: Program Managers } \\
\text { and Key Program Staff } \\
39\end{array}$ \\
\hline
\end{tabular}

FTE, full-time equivalent; CORD, CORD, the Childhood Obesity Research Demonstration project.

an institution's systems (e.g., electronic health record [EHR] changes), continuing education efforts, and changes in institutional policies. Another example of institutionalization is the cross-institutional partnerships or collaborations that will be measured using the Wilder Collaboration Factors Inventory. ${ }^{48}$ This measure is to be completed by members of the CORD community coalitions and measures the degree of institutionalization of the program in the community as evidenced by partnerships and collaborations resulting from the program.

Community capacity is the potential for the community to support CORD projects and activities through availability and involvement of organizations and structures. Strong community capacity can be operationalized by supportive polices and standard practices, strategic planning, funding priorities consistent with program components and goals, and stability of these elements through systems, organizations, and policies. ${ }^{44}$ We developed the Policy Indicator Checklist (PIC) to measure the presence and intensity of policies in communities, schools, and child care sectors that support PA and nutrition, and discourage consumption of sugar-sweetened beverages and caloriedense foods. ${ }^{49}$ The PIC will be completed by the ECCORD team and involves the auditing of public records of local and state policies to evaluate the need for establishment, strengthening, or maintenance of strategies to prevent obesity and promote health among partners and communities. Geographically linked and publicly available data from the US Census Bureau (ethnic density, neighborhood household income, educational attainment, and age characteristics), community websites and geographic information systems (GIS) departments (availability of parks and bicycle trails), the USDA Economic Research Service (access to supermarkets), and Esri

\section{Table 8. Community-Level Measures}

\begin{tabular}{|c|c|c|}
\hline Measures & Example items & Method source(s) \\
\hline Population size & Population size for metro- or micropolitan statistical areas & US Census \\
\hline Population density & Population density for metro- or micropolitan statistical areas & US Census \\
\hline Per-capita income & Per-capita income for metro- or micropolitan statistical areas & US Census \\
\hline $\begin{array}{l}\text { Availability/proximity/ } \\
\text { density of PA resources }\end{array}$ & $\begin{array}{l}\text { Does your local government have a written or official } \\
\text { objective to install bicycle racks at public facilities, such } \\
\text { as public parks, government buildings, or transit stations? }\end{array}$ & $\begin{array}{l}\text { Community Based Surveillance } \\
\text { of Healthy Eating/Active Living } \\
\text { (CBS) instrument }\end{array}$ \\
\hline $\begin{array}{l}\text { Availability/proximity/ } \\
\text { density of fast food resources }\end{array}$ & $\begin{array}{l}\text { Does your local government have pricing incentives } \\
\text { to promote the purchase of healthier foods and beverages } \\
\text { sold in local government buildings, including cafeteria } \\
\text { or vending machines? }\end{array}$ & CBS instrument ${ }^{40}$ \\
\hline $\begin{array}{l}\text { Availability/proximity/ } \\
\text { density of fresh food resources }\end{array}$ & $\begin{array}{l}\text { Does your local government currently use any of the following } \\
\text { to encourage supermarkets and other full-service grocery } \\
\text { stores to open stores? }\end{array}$ & CBS instrument ${ }^{40}$ \\
\hline $\begin{array}{l}\text { Policy and environmental } \\
\text { audit responses }\end{array}$ & $\begin{array}{l}\text { Does your local government have any of the following policies } \\
\text { or budget provisions related to parks or outdoor recreation areas? }\end{array}$ & CBS instrument ${ }^{40}$ \\
\hline
\end{tabular}

PA, physical activity. 


\begin{tabular}{|c|c|c|c|}
\hline Construct & Measure & Example source & Example item \\
\hline Replicability & $\begin{array}{l}\text { Complexity of programs } \\
\text { and activities at project sites } \\
\text { Utilization of existing activities, } \\
\text { resources, and materials }\end{array}$ & $\begin{array}{l}\text { Program components } \\
\text { checklist } \\
\text { Qualitative interviews } \\
\text { from site key informants }\end{array}$ & $\begin{array}{l}\text { Number of intervention aspects implemented } \\
\text { What, if any, available resources } \\
\text { or materials contributed most } \\
\text { to the program's success? }\end{array}$ \\
\hline $\begin{array}{l}\text { Continuation } \\
\text { of benefits }\end{array}$ & $\begin{array}{l}\text { Extension of program components } \\
\text { beyond planned sample } \\
\text { Long-term behavioral } \\
\text { and health outcomes }\end{array}$ & $\begin{array}{l}\text { Qualitative interviews } \\
\text { from site investigators } \\
\text { Behavioral Risk Factor } \\
\text { Surveillance System }\end{array}$ & $\begin{array}{l}\text { What unintended outcomes, both } \\
\text { positive and negative, are occurring } \\
\text { as a result of your site's program activities? } \\
\text { Obesity prevalence } \\
\text { Fruit and vegetable consumption } \\
\text { Participation in physical activity }\end{array}$ \\
\hline \multirow[t]{2}{*}{ Institutionalization } & $\begin{array}{l}\text { Level of support for implementation } \\
\text { from organizations }\end{array}$ & $\begin{array}{l}\text { Qualitative interviews } \\
\text { from site key informants }\end{array}$ & $\begin{array}{l}\text { To what extent have the people you } \\
\text { work with embraced potential policy } \\
\text { and environmental changes that your } \\
\text { program encourages? }\end{array}$ \\
\hline & $\begin{array}{l}\text { Cross-institutional partnerships } \\
\text { or collaborations }\end{array}$ & $\begin{array}{l}\text { Wilder Collaboration } \\
\text { Factors Inventory }\end{array}$ & $\begin{array}{l}\text { All the organizations that we need } \\
\text { to be members of this collaborative } \\
\text { group have become members of the group } \\
\text { (rate from "Strongly agree" to "Strongly disagree"). }\end{array}$ \\
\hline \multirow[t]{2}{*}{$\begin{array}{l}\text { Community } \\
\text { capacity }\end{array}$} & $\begin{array}{l}\text { Presence and intensity of local } \\
\text { and regional policies }\end{array}$ & Policy Indicator Checklist & $\begin{array}{l}\text { Restrictions on calorie-dense foods } \\
\text { or sugar-sweetened beverages within schools } \\
\text { Time requirements for physical education courses }\end{array}$ \\
\hline & $\begin{array}{l}\text { Existence and stability of community } \\
\text { goods, services, and other resources }\end{array}$ & $\begin{array}{l}\text { Lists and GIS files from } \\
\text { local government websites } \\
\text { ArcGIS Business Analyst (Esri) }\end{array}$ & $\begin{array}{l}\text { Access to parks } \\
\text { Access to fast food restaurants or supermarkets }\end{array}$ \\
\hline
\end{tabular}

CORD, the Childhood Obesity Research Demonstration project; GIS, geographic information systems.

ArcGIS Business Analyst (density of fast food restaurants) will provide information about the existence and stability of their goods, services, and resources. These contextual data will support in-depth comparisons of intervention sustainability across communities, based on all other qualitative and quantitative measures (Table 9).

\section{Cost Analyses}

Detailed information on the costs for training providers, delivering interventions in settings, and supply of equipment and other resources will be collected in a consistent manner by all projects. EC-CORD will compile and code these data for each activity using standard cost categories (labor, purchases, and in-kind). EC-CORD will facilitate retrieval of information at the three projects by abstracting financial reports, budget sheets, and ledgers from each project to create a standard format for the cost data. We will gauge the level of resolution that may be present in the cost data for each CORD project. For example, the projects were asked to track data on total costs per category, expenditures on the specific project activities (training staff, educating families, and providing equipment and supplies) and costs for categories and activities within each setting (totals by person/service/line item) will be used to assess the costs associated with replication, scalability, and sustainability of programs. The costs will be assessed longi- tudinally; costs at the start of an intervention are typically higher than those for maintaining activities in interventions and can change as programs are scaled up.

Furthermore, the benefits of CORD projects to the participating children will be assessed using comprehensive longitudinal models that take into account heterogeneity among populations. ${ }^{22,23}$ The expenditures on different components of interventions are likely to affect outcomes such as reductions in the speed of weight gain among children and improvements in their quality-of-life indicators. In addition, parents of children, especially in the intervention groups, will acquire useful information by participating in their children's activities. For example, if overweight parents of children in the intervention group lose weight, then we can use the results in the literature to argue that "positive externalities" (e.g., spinoffs or "ripple effects") owing to childhood obesity interventions are likely to reduce chronic disease burden among adults. This will be a direct and measurable public health impact. In addition, we will investigate the interventions that will have maximum benefits for specific communities. For example, if most parents are overweight and have low education levels in CA-CORD, then programs aimed at the family unit, including both parents and their young children, may be most effective. Such issues will be investigated using models estimated in the longitudinal data analyses. 
The final part of the cost analyses will assess the benefits that can be gained per dollar invested in each setting and across the communities. We will investigate the extent to which interventions can be regarded as being cost-effective in terms of the costs of attaining changes in the child activity and diet behaviors, weight, and quality-of-life measures. Community characteristics, such as levels of parental education and incomes, will be taken into account in assessing cost-effectiveness of interventions. Moreover, there are methodological issues arising in the definitions of cost-effectiveness that need to be addressed. For example, assessment of whether an intervention is cost-effective depends on there being statistically significant effects of the intervention on child activity and diet behaviors, weight, and quality-of-life measures. Only when there are significant benefits of interventions can one address the cost-effectiveness aspects. The estimated parameters from comprehensive dynamic random-effects models using the longitudinal data from CORD projects will shed light on the cost-effectiveness issues. In particular, we will appraise the relative magnitudes of estimated short- and long-run effects of variables on the outcomes and compute confidence intervals for the benefits accrued from the interventions. ${ }^{23}$ By taking into account the various effects of interventions on child and family well-being and the costs of intervention components, the research will provide useful insights into cost-effectiveness of interventions for preventing childhood obesity. Such findings will also be useful for assessing the feasibility and scalability of interventions for preventing childhood obesity in future programs.

\section{Discussion}

Planning and conducting a comprehensive evaluation of three independently designed projects implemented in eight different communities presents substantial challenges, including heterogeneity in populations, interventions, geographic locations, sociopolitical environments, measurement methods, and timelines. ${ }^{8}$ This article describes the evaluation plan for analyzing the data from the three independently designed and implemented CORD projects. A unifying framework identifies commonalities among the three projects to inform and structure each component of the evaluation. The resulting plan includes evaluation of process, impact, and sustainability. In addition, the research will develop a framework for assessing the short- and long-term costs and benefits for these childhood obesity prevention interventions. This plan describes our general approach to evaluating the pooled data from all three projects. The plan outlines the objectives and methods for each component of the evaluation while allowing flexibility to adjust, as needed, to issues that may arise once the full data are reported. The results of the evaluation will be used to determine whether multilevel, multisector programs integrating public health and primary care interventions are appropriate for national implementation in diverse communities.

\section{Conclusions}

EC-CORD will analyze the pooled data from three independent multilevel, multisector projects designed to induce environmental, systems, and policy changes that impact childhood obesity. The key to pooling and analyzing data from multiple projects is the CORD model framework used by all projects. The overarching logic model allows for categorizing the independent project components in comparable terms, common measures for the behavioral and health outcomes and important covariates, and a standardized approach to collecting and managing large amounts of data. The CORD project's cross-site evaluation approach includes plans for comprehensive assessments of processes, impact, sustainability, and costs.

\section{Acknowledgments}

This research was supported, in part, by cooperative agreement RFA-DP-11-007 (grant U18DP003350) from the CDC. The content is solely the responsibility of the authors and does not necessarily represent the official views of the CDC.

\section{Author Disclosure Statement}

No competing financial interests exist.

\section{References}

1. Taveras EM, Blaine RE, Davison KK, et al. Design and implementation of the Mass in Motion Kids Childhood Obesity Research Demonstration (MA-CORD) study. Child Obes 2014; $11: 11-22$

2. Ayala GX, Ibarra L, Binggeli-Vallarta A, et al. Our Choice/ Nuestra Opción: The Imperial County, California Childhood Obesity Research Demonstration study (CA-CORD). Child Obes 2014;11:37-47.

3. Hoelscher DM, Butte NF, Barlow S, et al. A systems approach to childhood obesity prevention and treatment: The Texas Child Obesity Research Demonstration (TX CORD) project. Child Obes 2014;11:71-91.

4. Department of Health and Human Services. Affordable Care Act (ACA): Childhood obesity research demonstration funding opportunity announcement (RFA-DP-11-007). [Archived announcement]. 2011. Available at www.grants.gov/web/grants/searchgrants.html?keywords $=\% 22$ childhood $\% 20$ obesity $\% 20$ research $\%$ 20demonstration\%22 Last accessed January 20, 2014.

5. Williams NA, Dooyema CA, Foltz JL, et al. The Childhood Obesity Research Demonstration (CDC-CORD) project: A team approach for supporting a multisite, multisector intervention. Child Obes 2014;11:104-108.

6. Dooyema CA, Belay B, Foltz JL, et al. The Childhood Obesity Research Demonstration project: A comprehensive community approach to reduce childhood obesity. Child Obes 2013;9:454-459.

7. Dietz W, Lee J, Wechsler H, et al. Health plans' role in preventing overweight in children and adolescents. Health Aff (Millwood) 2007;26:430-440.

8. Foltz JL, Dooyema CA, Belay B, et al. Childhood Obesity Research Demonstration (CORD): Commonalities, differences 
and opportunities in a multi-site project. Child Obes 2014;11: 104-108.

9. Davison KK, Falbe J, Taveras EM, et al. Evaluation overview for the Mass in Motion Kids Childhood Obesity Research Demonstration (CORD) study. Child Obes 2014;11:23-36.

10. Griffith L, van den Heuvel E, Fortier I, et al. Harmonization of cognitive measures in individual participant data and aggregate data meta-analysis (AHRQ publication no. 13-EHC040-EF). Agency for Healthcare Research and Quality: Rockville, MD, 2013.

11. Blettner M, Sauerbrei W, Schlehofer B, et al. Traditional reviews, meta-analyses and pooled analyses in epidemiology. Int J Epidemiol 1999;28:1-9.

12. Curran PJ, Hussong AM. Integrative data analysis: The simultaneous analysis of multiple data sets. Psychol Methods 2009;14: 81-100.

13. Allen J, Inder KJ, Lewin TJ, et al. Integrating and extending cohort studies: Lessons from the eXtending Treatments, Education and Networks in Depression (xTEND) study. BMC Med Res Methodol 2013;13:122.

14. Sacher PM, Kolotourou M, Chadwick PM, et al. Randomized controlled trial of the MEND program: A family-based community intervention for childhood obesity. Obesity (Silver Spring) 2010;18(Suppl 1):S62-S68.

15. Belle SH, Czaja SJ, Schulz R, et al. Using a new taxonomy to combine the uncombinable: Integrating results across diverse interventions. Psychol Aging 2003;18:396-405.

16. Schneider M, Hall WJ, Hernandez AE, et al. Rationale, design and methods for process evaluation in the HEALTHY study. Int J Obes (Lond) 2009;33(Suppl 4):S60-S67.

17. Steckler AB, Linnan L. Process Evaluation for Public Health Interventions and Research. Jossey-Bass: San Francisco, CA, 2002.

18. Hall WJ, Zeveloff A, Steckler A, et al. Process evaluation results from the HEALTHY physical education intervention. Health Educ Res 2012;27:307-318.

19. Thiagarajah K, Fly AD, Hoelscher DM, et al. Validating the food behavior questions from the elementary school SPAN questionnaire. J Nutr Educ Behav 2008;40:305-310.

20. Chervin RD, Hedger K, Dillon JE, et al. Pediatric sleep questionnaire (PSQ): Validity and reliability of scales for sleep-disordered breathing, snoring, sleepiness, and behavioral problems. Sleep Med 2000;1:21-32.

21. Varni JW, Burwinkle TM, Seid M, et al. The PedsQL 4.0 as a pediatric population health measure: Feasibility, reliability, and validity. Ambul Pediatr 2003;3:329-341.

22. Bhargava A, Guthrie JF. Unhealthy eating habits, physical exercise and macronutrient intakes are predictors of anthropometric indicators in the Women's Health Trial: Feasibility study in minority populations. Br J Nutr 2002;88:719-728.

23. Bhargava A, Sargan JD. Estimating dynamic random effects models from panel data covering short time periods. Econometrica 1983;51:1635-1659.

24. Cooper H, Patall EA. The relative benefits of meta-analysis conducted with individual participant data versus aggregated data. Psychol Methods 2009;14:165-176.

25. Stewart GB, Altman DG, Askie LM, et al. Statistical analysis of individual participant data meta-analyses: A comparison of methods and recommendations for practice. PLoS One 2012;7: e46042.

26. Murray DM, Hannan PJ, Baker WL. A Monte Carlo study of alternative responses to intraclass correlation in community trials. Is it ever possible to avoid Cornfield's penalties? Eval Rev 1996;20:313-337.
27. Centers for Disease Control and Prevention. National Health and Nutrition Examination Survey (NHANES): Anthropometry Procedures Manual. 2009, pp. 1-120. Available at www.cdc.gov/nchs/ data/nhanes/nhanes_09_10/BodyMeasures_09.pdf Last accessed February 15, 2014.

28. Larios SE, Ayala GX, Arredondo EM, et al. Development and validation of a scale to measure Latino parenting strategies related to children's obesigenic behaviors. The Parenting strategies for Eating and Activity Scale (PEAS). Appetite 2009;52: $166-172$.

29. Centers for Disease Control and Prevention. Behavioral Risk Factor Surveillance System Questionnaire. 2011, pp. 1-89. Available at www.cdc.gov/brfss/annual_data/pdf-ques/2011brfss.pdf Last accessed February 5, 2014.

30. Centers for Disease Control and Prevention. Plan and operation of the Third National Health and Nutrition Examination Survey, 1988-94. Series 1: Programs and collection procedures. Vital Health Stat 1 1994;No. 32:1-407.

31. Bell M, Fink K, Barker P, et al. State of Alaska measuring height/ weight and calculating BMI guidelines for schools. Department of Health and Social Services: Anchorage, AK, 2011.

32. Cruz T, Canaca G, Davis S, et al. BMI Surveillance in New Mexico: A Training Manual for Measuring Height and Weight in Schools. New Mexico Department of Health: Santa Fe, NM: 2010.

33. Centers for Disease Control and Prevention, Brener ND, Kann L, et al. Methodology of the Youth Risk Behavior Surveillance System-2013. MMWR Recomm Rep 2013;62:1-20.

34. Liao Y, Tucker P, Giles WH. Health status among REACH 2010 communities, 2001-2002. Ethn Dis 2004;14(3 Suppl 1):S9-S13.

35. Ammerman AS, Ward DS, Benjamin SE, et al. An intervention to promote healthy weight: Nutrition and Physical Activity SelfAssessment for Child Care (NAP SACC) theory and design. Prev Chronic Dis 2007;4:A67.

36. RTI International. Early Childhood Longitudinal Program-Preschool Center Director Questionnaire. 2005. Available at https://nces.ed .gov/ecls/pdf/birth/director_saq.pdf Last accessed January 20, 2014.

37. Alliance for Healthier Generation. Healthy Schools Inventory worksheet. 2011. Available at https://schools.healthiergeneration.org Last accessed January 20, 2014.

38. Hoelscher DM, Day RS, Kelder SH, et al. Reproducibility and validity of the secondary level School-Based Nutrition Monitoring student questionnaire. J Am Diet Assoc 2003;103:186-194.

39. National Center for Education Statistics. Common Core of Data (CCD). 2014. Available at http://nces.ed.gov/ccd Last accessed February 20, 2014.

40. Centers for Disease Control and Prevention. Children's BMI tool for schools-Assessing Your Weight: Children's BMI tool for schools. Centers for Disease Control and Prevention: Atlanta, GA, 2011.

41. Centers for Disease Control and Prevention. Swift Worksite Assessment and Translation (SWAT) implementation guide. Centers for Disease Control and Prevention: Atlanta, GA, 2010.

42. Centers for Disease Control and Prevention, National Center for Chronic Disease Prevention and Health Promotion, Division of Nutrition, Physical Activity and Obesity. Pilot study of Community-Based Surveillance of Supports for Healthy Eating/Active Living (HE/AL). Centers for Disease Control and Prevention: Atlanta, GA, 2014.

43. Bryce J, Victora CG, Habicht JP, et al. The multi-country evaluation of the integrated management of childhood illness strategy: Lessons for the evaluation of public health interventions. Am J Public Health 2004;94:406-415. 
44. Shediac-Rizkallah MC, Bone LR. Planning for the sustainability of community-based health programs: Conceptual frameworks and future directions for research, practice and policy. Health Educ Res 1998; 13:87-108.

45. Mullen PD, Evans D, Forster J, et al. Settings as an important dimension in health education/promotion policy, programs, and research. Health Educ Q 1995;22:329-345.

46. Lee RE, Medina AV, Mama SK, et al. Health is Power: An ecological, theory-based health intervention for women of color. Contemp Clin Trials 2011;32:916-923.

47. Earls F, Carlson M. The social ecology of child health and wellbeing. Annu Rev Public Health 2001;22:143-166.

48. Mattessich PW, Monsey B, Murray-Close M. Wilder Collaboration Factors Inventory: Assessing your collaboration's strengths and weaknesses. Fieldstone Alliance: St. Paul, MN, 2001.
49. Lee RE, Hallett AM, Parker N, et al. Measuring policies for sugar sweetened beverages and calorie dense foods across multiple sectors: The Policy Indicator Checklist (in press).

Address correspondence to:

Daniel P. O'Connor, PhD Associate Professor Department of Health and Human Performance Texas Obesity Research Center University of Houston 3855 Holman GAR104 Houston, TX 77204-6015 E-mail:dpoconno@central.uh.edu 